\title{
Erratum to: Validation of the custo screen pediatric blood pressure monitor according to the European Society of Hypertension International Protocol revision 2010
}

\author{
Beate Beime $^{1}$ - Cornelia Deutsch ${ }^{1} \cdot$ Ralf Krüger $^{1} \cdot$ Andreas Wolf $^{2} \cdot$ Peter Müller $^{2}$. \\ Gertrud Hammel $^{3} \cdot$ Peter Bramlage $^{1}$
}

Published online: 4 May 2017

(C) Springer-Verlag Berlin Heidelberg 2017

\section{Erratum to: Eur J Pediatr}

DOI 10.1007/s00431-017-2874-3

The original version of this article, unfortunately, contained errors.
In Table 5, entries "Passed" and "Passed and Result" were not properly aligned under Grade 2 and Grade 3. The "Passed" entries in column 4 should be moved under Grade 2 and "Passed and Result" entries under Grade 3.

The correct Table is as follows:

The online version of the original article can be found at http://dx.doi.org/ 10.1007/s00431-017-2874-3

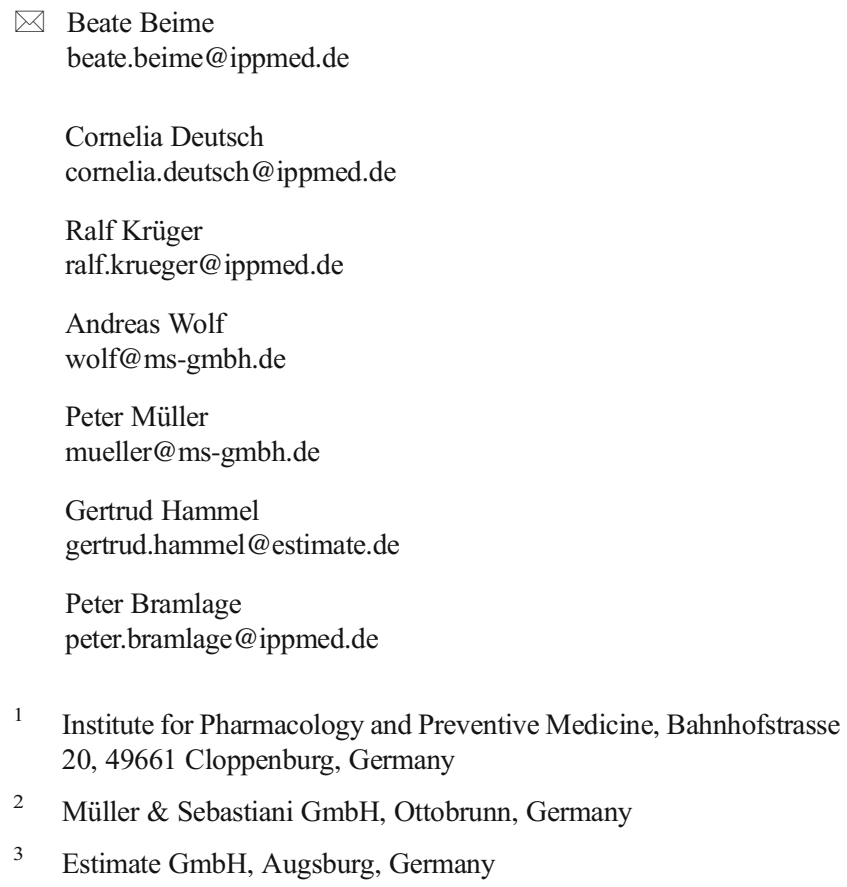

3 Estimate $\mathrm{GmbH}$, Augsburg, Germany 
Table 5 Validation Results

\begin{tabular}{llllll}
\hline Part 1 & $\begin{array}{l}\leq 5 \\
\mathrm{mmHg}\end{array}$ & $\begin{array}{l}\leq 10 \\
\mathrm{mmHg}\end{array}$ & $\begin{array}{l}\leq 15 \\
\mathrm{mmHg}\end{array}$ & Grade 1 & $\begin{array}{l}\text { Mean } \pm \mathrm{SD} \\
(\mathrm{mmHg})\end{array}$ \\
$\begin{array}{l}\text { Pass requirements } \\
\text { Two of }\end{array}$ & 73 & 87 & 96 & \\
All of & 65 & 81 & 93 & & \\
Achieved & & & & \\
SBF & 95 & 99 & 99 & Passed & $-1.4 \pm 3.0$ \\
DBF & 91 & 99 & 99 & Passed & $-0.7 \pm 3.2$ \\
Part 2 & $2 / 3 \leq 5 \mathrm{mmHg}$ & $0 / 3 \leq 5 \mathrm{mmHg}$ & Grade 2 & Grade 3 \\
Pass requirements & $\geq 24$ & $\leq 3$ & & & \\
Achieved & 32 & & & Passed & \\
SBF & 33 & 0 & & Passed & \\
DBF & & 0 & & & Result \\
Part 3 & & & & & Passed \\
\hline
\end{tabular}

$S B P$ systolic blood pressure, $D B P$ diastolic blood pressure, $S D$ standard deviation 